\title{
CHARACTERIZATION OF THE BAND BENDING IN ZnSe-GaAs HETEROJUNCTIONS BY RAMAN SCATTERING*
}

\author{
W. BALA, \\ Institute of Physics, N. Copernicus University, Grudziądzka 5/7, 87-100 Torun, Poland
}

\section{Drozdowski and M. Kozielski}

Institute of Physics, Poznan Technical University, Piotrowo 3, 60-965 Poznań, Poland

(Received August 8, 1990)

\begin{abstract}
The band bending effect at the $\mathrm{ZnSe}-\mathrm{GaAs}$ interface was studied by means of Raman scattering induced by electric-field related to longitudinal-optical (LO) phonons. It has been shown that the variation of the band bending in GaAs can be modified by changes in the electron concentration of $\mathrm{ZnSe}$ epilayer and the variation of the sample temperature.
\end{abstract}

PACS numbers: $78.30 . \mathrm{Hv}, 61.70 . \mathrm{Wp}$

In recent years Raman scattering in semiconductors has been used as a useful tool to study the electrooptical properties of interfaces in heterostructures [1-3]. This kind of studies has been mainly concentrated on III-V heterostructures. Much less attention was given to the effects induced by a II-VI epilayer when grown on III-V semiconductor substrate (e.g. barrier height, Fermi level pinning, and recombination velocity [4]).

In this paper we present Raman scattering spectra for ZnSe epilayers grown by molecular beam epitaxy on GaAs substrate [5]. The ZnSe epilayers were deposited at $555 \mathrm{~K}$ on the (001) surface of GaAs substrates with bulk carrier concentration of $2 \times 10^{18}$ electrons $/ \mathrm{cm}^{3}$ from elemental sources of $\mathrm{ZnSe}$. The growth rates were in the range of $0.4-0.8 \mu \mathrm{m} / \mathrm{h}$. The $\mathrm{Se} / \mathrm{Zn}$ beam pressure ratio of about 2 was employed.

The Raman polarized spectra were measured at room temperature and $600 \mathrm{~K}$ using back-scattering geometry. An argon ion laser operating at $458 \mathrm{~nm}$ with the output power $140 \mathrm{~mW}$ as a source of light was used. The more details of the measurement were described elsewhere [6].

*This work was supported in part by CPBP 01.08 (Poznań) and 01.06 (Toruń). 


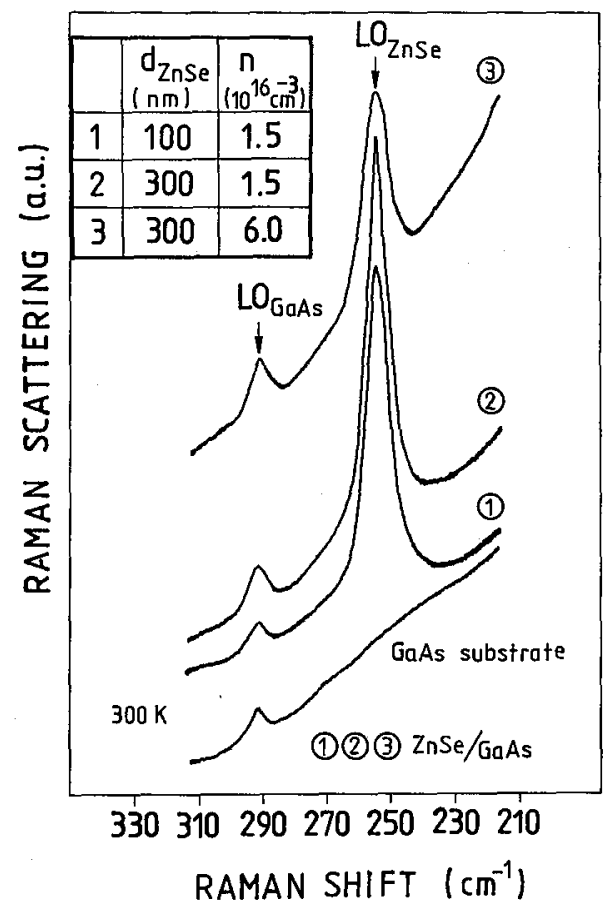

Fig. 1. Raman spectra of the ZnSe-GaAs heterojunctions with different thicknesses and different free carrier concentrations of the ZnSe epilayer obtained at RT. For comparison the Raman spectrum of the air-exposed GaAs surface is also included.

The properties of the $\mathrm{ZnSe}$ epilayers with both different thicknesses and different free carrier concentrations were studied with electric-field induced Raman scattering by LO-phonons. In Fig. 1 the typical polarized Raman spectra for selected values of free carrier concentration and different thicknesses of $\mathrm{ZnSe}$ epilayers are presented. The peak frequencies at room temperature are $292 \mathrm{~cm}^{-1}$ and $250 \mathrm{~cm}^{-1}$ for $\mathrm{LO}_{\mathrm{GaAs}}$ and $\mathrm{LO}_{\mathrm{ZnSe}}$, respectively. As seen from the Fig. 1, the $\mathrm{LO}_{\mathrm{GaAs}}$ intensities are stronger for the $\mathrm{ZnSe}-\mathrm{GaAs}$ heterojunctions than for the GaAs substrate. When compared $\mathrm{LO}_{\mathrm{GaAs}}$ mode in $\mathrm{ZnSe}-\mathrm{GaAs}$ heterostructures with the air-exposed surfaces of the GaAs substrate as a reference, the $\mathrm{LO}_{\mathrm{GaAs}}$ intensities increased when the free carrier concentration in $\mathrm{ZnSe}$ epilayer increased (Fig. 1, curve 1 and 3). Similar behaviour was observed when the thicknesses of the ZnSe epilayers increased (Fig. 1, curve 1 and 2). As one can also see from Fig. 1 (curve 2 and 3 ) the $\mathrm{LO}_{\mathrm{ZnSe}}$ mode broadens and its intensity decreases as the free carrier concentration increases. These results suggest that the plasmon in $n$ - $\mathrm{ZnSe}$ epilayers has large damping rates and the $\mathrm{LO}_{\mathrm{ZnSe}}$ phonon in thicker (and with higher free carrier concentration) epilayers is coupled with the plasmon. The line shape analysis of the coupled $\mathrm{LO}_{\mathrm{ZnSe}}$ mode has shown that the dominant 


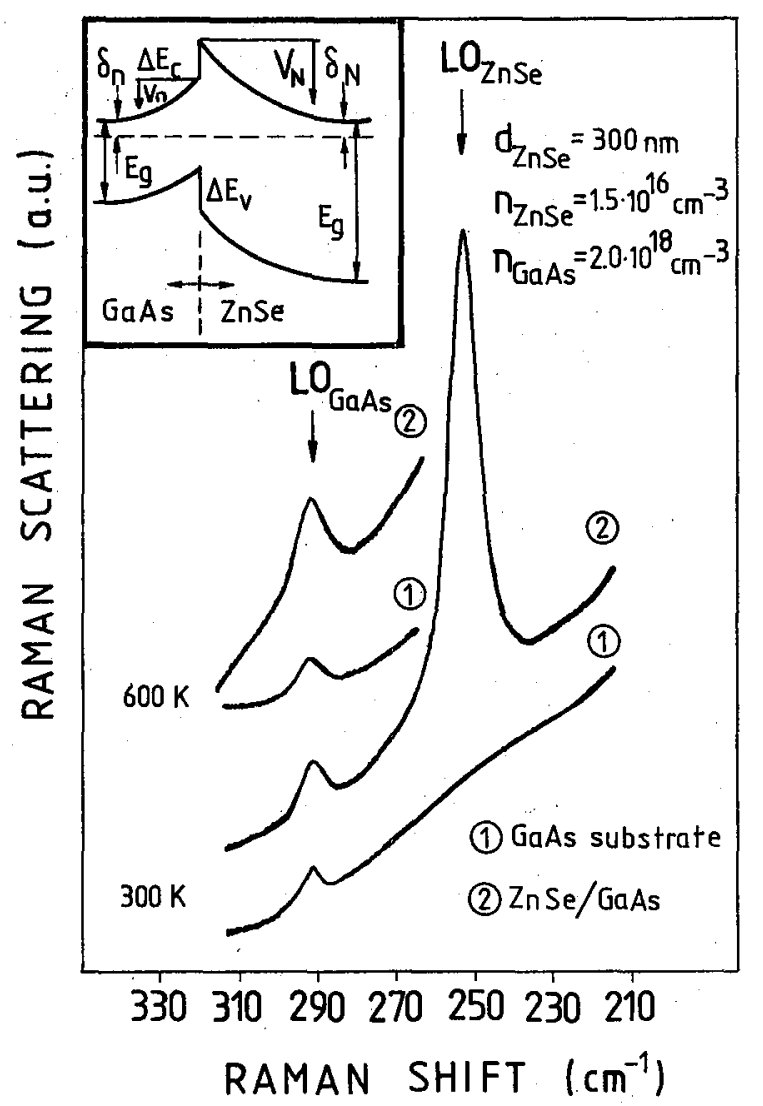

Fig. 2. Raman spectra of the $\mathrm{ZnSe}-\mathrm{GaAs}$ heterojunction and the air-exposed $\mathrm{GaAs}$ surface obtained at different temperatures. In inset - the band structure of the $n$ - $\mathrm{ZnSe} / n$-GaAs heterojunction, where: $\Delta E_{\mathrm{c}}, \Delta E_{\mathrm{v}}$ - the offsets in the conduction and valence band. $\delta_{n}, \delta_{N}$ - the Fermi level position measured from the bottom conduction band in $n$-type GaAs and $\mathrm{ZnSe}$, respectively. $V_{n}, V_{N}$ - the band bending of the conduction band of the $\mathrm{GaAs}$ and $\mathrm{ZnSe}$, respectively. 
phonon scattering in $n$-type $\mathrm{ZnSe}$ epilayers is caused by the deformation potential, electro-optical and charge density fluctuation mechanisms [7, 8]. The electric-field induced scattering mechanism is the main scattering process for the $\mathrm{LO}_{\mathrm{GaAs}}$ mode. Moreover, the variations of the $\mathrm{LO}_{\mathrm{GaAs}}$ intensities with the thickness of $\mathrm{ZnSe}$ epilayer at the $\mathrm{ZnSe}-\mathrm{GaAs}$ interface indicate that the electric field has changed here as compared with the situation at the air-exposed surface of the GaAs substrate $[1,9]$. The electric-field-induced contribution to the LO intensities is in the first order linearly proportional to the magnitude of the band bendings $\left(V_{n}-\right.$ for $\mathrm{GaAs}$ and $V_{N}-$ for $\left.\mathrm{ZnSe}\right)[1,9]$. The ratio $\alpha$ of the intensities between the $L O_{\text {GaAs }}$ peaks of the $\mathrm{ZnSe}-\mathrm{GaAs}$ heterojunctions and the air-exposed surface of GaAs at RT are 2.17 and 1.86 for $d=100 \mathrm{~nm}$ and $d=300 \mathrm{~nm}$ thick ZnSe epilayer, respectively. We have assumed that for the air-exposed GaAs surface the Fermi level is pinned at around midgap and the band bending of GaAs, $V_{n}=0.8 \mathrm{eV}$ [10]. For this value the band bending at $\mathrm{ZnSe}-\mathrm{GaAs}$ interface $V_{n} \times \alpha$ are equal $1.60 \mathrm{eV}(d=300 \mathrm{~nm})$ and $1.86 \mathrm{eV}(d=100 \mathrm{~nm})$. These values are in good agreement with the values estimated by photo-luminescence measurement [2]. Figure 2 shows the first order Raman spectra measured at RT and $600 \mathrm{~K}$ for the typical ZnSe-GaAs heterostructures and for an air-exposed, uncoated surface of the GaAs substrate. The changes in the intensity of the $\mathrm{LO}_{\mathrm{GaAs}}$ mode with temperature displayed in Fig. 2 indicate that the $\mathrm{ZnSe}$ epilayers are modifying the band bending at the interface [1]. The higher $\mathrm{LO}_{\mathrm{GaAs}}$ intensities correspond to the increased strengths of the electric field and higher surface potentials $\left(V_{n}\right)[9]$.

\section{References}

[1] D.J. Olego, Phys. Rev. B 39, 12743 (1989).

[2] D.J. Olego, Appl. Phys. Lelt. 51, 1422 (1987).

[3] S. Colak, T. Marshall, D. Cammack, Solid-State Electron. 32, 647 (1989).

[4] D.J. Olego, K. Shahzad, J. Petruzzello, D. Cammack, Phys. Rev. B 36, 7674 (1987).

[5] W. Bała, F. Firszt, in Proc. 3rd Conf. Surface Physics, Zakopane 1988, Vol. 5, eds. J. Kapelewski, J. Rutkowski, L. Solarz, Wydawn. Uniwer. Lódz., Łódź 1989, p. 27.

[6] M. Kozielski, M. Drozdowski, W. Bała, F. Firszt, Acta Phys. Pol. A73, 369 (1988).

[7] G. Irmer, V.V. Toporov, B.H. Bairamov, J. Monecke, Phys. Status Solidi B 119, 595 (1983).

[8] W. Bala, M. Drozdowski, M. Kozielski, in Proc. 9th Internat. Conf. on Raman Spectroscopy, London 1988, eds. R.J.H. Clark, D.A. Long, Wiley, Chichester 1988, p. 88.

[9] G. Abstreiter, M. Cardona, A. Pinczuk, in Light Scatlering in Solids IV, eds. M. Cardona, G. Guntherodt, Springer Verlag, Ireidelberg 1984.

[10] S.M. Sze, Physics of Semiconductor Devices, Wiley, New York 1981. 